\title{
Mathematical Model of Tubular Linear Induction Motor
}

\author{
Viacheslav Okhrimenko $^{1 *}$, Maiia Zbitnieva ${ }^{2}$ \\ ${ }^{1}$ Department of Power Supply and Power Consumption of Cities, O. M. Beketov National University of Urban Economi in \\ Kharkiv, 16 Marshala Bazhanova, Kharkiv 61002, Ukraine \\ ${ }^{2}$ Kharkiv Humanitarian-Pedagogical Academy, 7 Shota Rustaveli Lane, Kharkiv 61000, Ukraine
}

Corresponding Author Email: monviktor@ukr.net

https://doi.org/10.18280/mmep.080113

Received: 15 November 2020

Accepted: 23 January 2021

\section{Keywords:}

coupled magnetization currents, electric field strength, geometric structure optimization, magnetic field induction, polar coordinate system, TLIM

\begin{abstract}
Problem of calculation of distribution of magnetic field induction in clearance of tubular linear induction motor (TLIM) is considered. Mathematical model is represented by Fredholm integral equations of second kind for complexes of electric field strength and density of coupled magnetization currents at interface of environments. Algorithm of calculation of distribution of magnetic field induction in TLIM clearance has been developed. Dependence of magnetic field induction in motor clearance on value of pole division is investigated. There is area of optimum pole pitch. Reliability of results of calculations on mathematical model is confirmed by their comparison with results obtained on physical model. Calculated dependence of induction on thickness of runner's iron circuit also has extreme character. Given model can be used at design stage of TLIM. Model allows calculating its optimal geometric dimensions based on criterion of maximum induction in motor clearance, taking into account physical properties of applied materials.
\end{abstract}

\section{INTRODUCTION}

Linear electric motors are widely used in drives of various mechanisms with translational motion of executive organs. Researchers and developers pay much attention to problems of improving their designs and calculation methods [1].

Tubular linear induction motors (TLIMs) are distinguished by their simplicity and low cost of design. Area of their use is constantly expanding: drives of manipulators and industrial robots; in mining, electric power and other industries. Researchers pay a lot of attention to problem of optimization of TLIM, perfection of their characteristics [2-4].

Problem of development of methods of calculation of TLIM [4, 5], accounting for edge effects [6], optimization of geometric dimensions of engine remains urgent.

\section{ANALYSIS OF RECENT RESEARCHERS AND PUBLICATIONS}

New method of calculation of linear asynchronous motors with inductors of limited length with flat, cylindrical or rotating working organs is proposed in work [2]. Information on developed three-phase tubular linear motors for mining machineries and single-phase linear motors for high-voltage switching devices is presented.

Problem of optimization of TLIM at design stage by modelling taking into account edge effects is considered in [6]. Many researchers use finite elements method [7]. Method of three-dimensional finite elements is applied for analysis and improvement of characteristics of TLIM in article [8].

Developers solve problem of choice of rational geometric structure that provides required energy characteristics, for example, efficiency of engine in process of designing TLIM. This problem can be solved by investigation of influence of geometric parameters on electromagnetic field in TLIM, which in general case is described by Maxwell system of equations. Analytical solution of Maxwell system of equations, due to complexity of geometric structure of TLIM, is not possible and problem is solved by numerical methods. One of solutions, transformation of original system of Maxwell equations into partial differential equations such as Laplace or Poisson equations [9]. However, calculated models obtained in this case do not allow investigate influence of geometric dimensions on characteristics of field in engine, since one of assumptions in such models is absence of grooves on inductor surface.

\section{FORMULATION OF PROBLEM}

It was proposed to use method of secondary sources [10] to study electromagnetic field in TLIM in work [11]. Problem is formulated in form of Fredholm integral equations of second nature for complexes of electric field strength and coupled magnetization currents $\sigma$ at border of division of environments with different magnetic permeabilities (stator steel - air, stator steel - stator winding, and runner steel - copper-coated runner surface). The resulting computational model of the engine makes it possible to study the influence of the geometric dimensions of the engine (pole division, coil thickness, etc.) and the physical properties of the materials used (magnetic permeability of the steel of the magnetic circuit, electrical conductivity) on the value of magnetic induction in the engine gap.

Aim of work was to refine mathematical model of TLIM, 
algorithm for its calculation and research of dependence of induction in engine gap on geometric dimensions of engine.

\section{CONSTRUCTION TLIM}

Device of tubular LIM is shown in Figure 1 [12]. Immovable stator of engine is installed in cylindrical housing 1. Steel clips 2 form stator magnetic circuit. Stator windings, made in form of flat coils 3 , are installed in clips. Clamping nuts 4 have bronze bushings 5 that serve as slides for movement of movable part - runner 7 . There is copper coating 6 that acts as winding of movable part on runner surface.

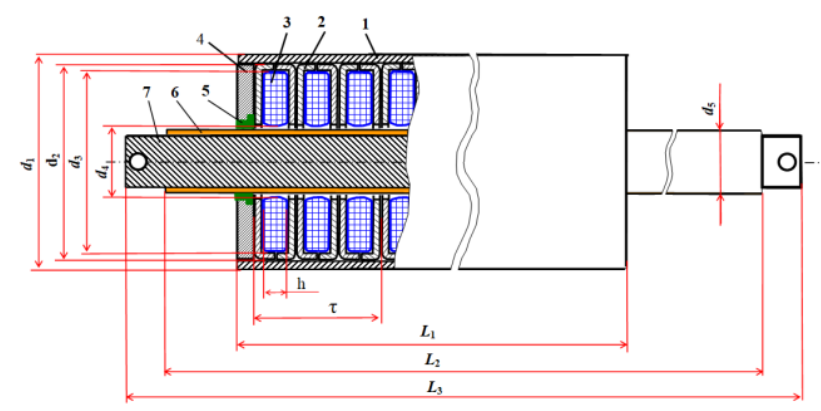

Figure 1. Device of tubular LIM

Stator winding is powered by three-phase current (Figure 2).

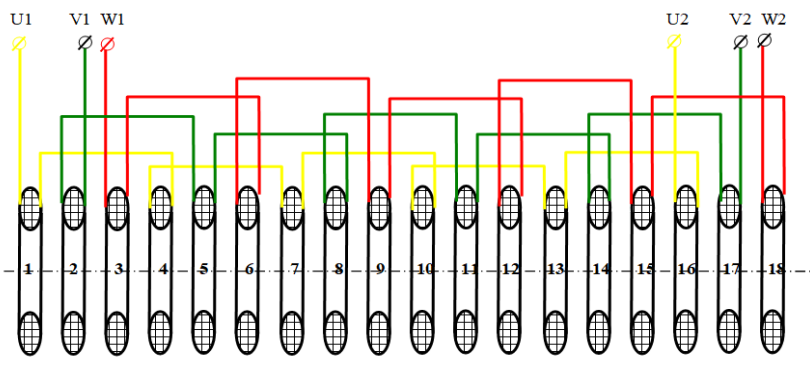

Figure 2. Stator coil connection diagram

Currents flowing in winding create alternating magnetic field in inhomogeneous medium of stator, consisting of steel, copper, insulation and air when stator winding is connected to three-phase network. This field induces eddy currents in runner copper sleeve, which affect resulting magnetic field of motor.

\section{MATEMATICAL MODEL OF TLIM}

Following assumptions are made in mathematical model.

Electromagnetic field in engine is quasi-stationary. Displacement currents in dielectric and, as a consequence, radiation can be neglected in this case. This assumption is quite true, since stator winding is powered from electric network with a frequency of $50 \mathrm{~Hz}$ and dimensions of motor elements are much less than wavelengthes of electromagnetic field. It is possible, without prejudice to accuracy of calculation, to neglect displacement currents in dielectric, and, consequently, radiation in this case.

Environment in which electromagnetic field is investigated is considered piecewise homogeneous. We are considered constant within limits of each conductor and each individual part of iron circuit, specific conductivity $\gamma$ and magnetic permeability $\mu$ in this case.

Assumption of constancy of specific conductivity $\gamma$ in metal conductors at ordinary temperatures is fulfilled at frequencies up to $1 \mathrm{MHz}$ [10]. Assumption of constant magnetic permeability $\mu$ is valid if induction in iron circuit of motor does not reach value at which nonlinear properties of used steel are affected.

Strength of electric and magnetic fields changes sinusoidally with time. We do not take into account phenomenon of hysteresis.

Winding is laid evenly within stator slots. This assumption is acceptable from the point of view of stator winding manufacturing technology.

Engine runner is copper-plated steel bar. Induced currents are induced in runner's copper coating under action of electromagnetic field of stator. We assume that induced currents penetrate only to depth of copper coating since conductivity of copper is much higher than conductivity of steel.

We will be considered field in engine in cylindrical coordinate system since design of it is axisymmetric. Scheme of computational model of TLIM is shown in Figure 3. Polar axis $\mathrm{Z}$ of cylindrical coordinate system is aligned with longitudinal axis of engine, and polar radius $\rho$ is aligned with left edge of stator.

Plane-meridian nature of field in engine allows, in order to reduce amount of calculations, to calculate electromagnetic field in one meridian plane. Plane $\varphi=0$ is chosen in model.

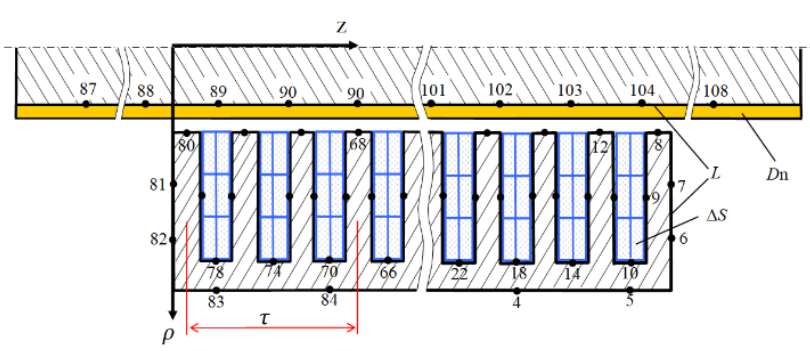

Figure 3. Design model TLIM

Electromagnetic field in engine with immovable runner is described by system of integral equations for complexes of electric field strength $\dot{\tilde{E}}$ and density of coupled magnetization currents $\dot{\tilde{\sigma}}[11]$.

$$
\begin{gathered}
\dot{\tilde{E}}(Q)+j \lambda_{0} \int_{D_{n}} \frac{\mu(M)}{\mu_{0}} \gamma(M) \dot{\tilde{E}}(M) T(Q, M) d S_{M}+ \\
+j \lambda_{0} \int_{L} \dot{\tilde{\sigma}}(M) T(Q, M) d L_{M}=\dot{F}_{1}(Q), \quad Q \in D_{n}, \\
\dot{\tilde{\sigma}}(Q)-\chi \int_{L} \dot{\tilde{\sigma}}(M) S(Q, M) d L_{M}- \\
-\chi \int_{D_{n}} \frac{\mu(M)}{\mu_{0}} \gamma(M) \dot{\tilde{E}}(Q, M) d S_{M}=\dot{F}_{2}(Q), \quad Q \in L,
\end{gathered}
$$

where: $Q$ and $M$ - fixed and current integration points; $\mu(M)$ - magnetic permeability in point $M$; $\gamma(M)$ - electroconductivity at point $M$; $\mu_{0}$ - magnetic constant;

$\lambda_{0}-$ coefficient determined by ratio 


$$
\lambda_{0}=\frac{\omega \mu_{0}}{2 \pi}
$$

$x-$ coefficient determined by ratio

$$
x=\frac{1}{\pi} \frac{\mu_{s t}-1}{\mu_{s t}+1}
$$

where: $\mu_{\text {st }}-$ magnetic permeability of steel.

Kernels $T(Q, M)$ and $S(Q, M)$ of integral equations (1) and (2) are determined by relations [11]

$$
\begin{gathered}
T(Q, M)=\left(\frac{2}{k}-k\right) K(k)-\frac{2}{k} E(k), \\
S(Q, M)=\frac{1}{2 \rho_{Q} \sqrt{\rho_{Q} \rho_{M}}}\left(f _ { 1 } ( k ) \left(\left(Z_{Q}-Z_{M}\right) \cos \left(\bar{s}_{Q}, \bar{e}_{\rho}\right)-\right.\right. \\
\left.\left.-\rho_{Q} \cos \left(\bar{s}_{Q}, \bar{e}_{Z}\right)\right)-f_{2}(k) \rho_{M} \cos \left(\bar{s}_{Q}, \bar{e}_{Z}\right)\right),
\end{gathered}
$$

where: $\rho_{\mathrm{Q}}$ and $\rho_{\mathrm{M}}-$ coordinate $\rho$ of points $Q$ and $M$;

$Z_{\mathrm{Q}}$ and $Z_{\mathrm{M}}$ - coordinate $\mathrm{Z}$ of points $Q$ and $M$;

$\bar{e}_{\rho}$ and $\bar{e}_{Z}-$ unit vectors of coordinate axes $\rho$ and $\mathrm{Z}$;

$\bar{s}_{Q}$ - unit vector of tangent to interface at point $Q$;

$k$-module of complete elliptic integrals $K(k)$ and $E(k)$

$$
k^{2}=\frac{4 \rho_{Q} \cdot \rho_{M}}{\left(\rho_{Q}+\rho_{M}\right)^{2}+\left(Z_{Q}-Z_{M}\right)^{2}} ;
$$

$K(k)$ and $E(k)$ - complete elliptic integrals of first and second kind [11]

$$
\begin{gathered}
K(k)=\int_{0}^{\pi / 2} \frac{d \rho}{\sqrt{1-k^{2} \sin ^{2} \rho}} \\
E(k)=\int_{0}^{\pi / 2} \sqrt{1-k^{2} \sin ^{2} \rho} d \rho ;
\end{gathered}
$$

$f_{1}(\mathrm{k})$ and $f_{2}(\mathrm{k})$ - functions of modulus of complete elliptic integrals of 1 st and 2 nd kind

$$
\begin{gathered}
f_{1}(k)=k\left(K(k) \frac{2-k^{2}}{2\left(1-k^{2}\right)} E(k),\right. \\
f_{2}(k)=\frac{k^{3}}{2\left(1-k^{2}\right)} E(k) .
\end{gathered}
$$

In Eqns. (1) and (2) denotes:

$$
\begin{aligned}
& \dot{\tilde{E}}(Q)=\sqrt{\rho_{Q}} \dot{E}(Q) ; \\
& \dot{\tilde{\sigma}}(Q)=\sqrt{\rho_{Q}} \dot{\sigma}(Q) .
\end{aligned}
$$

Right-hand sides of Eqns. (1) and (2) are determined by ratios [11]

$$
\dot{F}_{1}(Q)=-j \lambda_{0} \int_{S_{c}} \dot{\tilde{\sigma}}(N) T(Q, N) d S_{N}+\frac{\dot{\tilde{e}}_{e x t}(Q)}{2 \pi \sqrt{\rho_{Q}}},
$$

$$
\dot{F}_{2}(Q)=\chi \int_{S_{c}} \dot{\tilde{\delta}}(N) S(Q, N) d S_{N}
$$

where: $\dot{\tilde{\delta}}(N)=\sqrt{\rho_{N}} \dot{\delta}(N)$ - density of conduction currents at point $N$ of cross section of stator coils;

$S_{c}$ - area of section of stator coils;

$Q, N$ - fixed and current integration points;

$\dot{\tilde{e}}_{\text {ext }}(Q)$ - external emf, which is determined [11]

$\dot{\tilde{e}}_{\text {ext }}(Q)=\frac{2 \pi \rho_{\mathrm{Q}}}{\gamma_{\mathrm{k}}} \dot{\delta}(Q)+j \omega \mu_{0} \sqrt{\rho_{Q}} \int_{S_{c}} \dot{\delta}(N) T(Q, N) d S_{N}$.

System of Eqns. (1) - (2) has view in operator form

$$
\begin{gathered}
\dot{\tilde{E}}(Q)+j \lambda_{0} \mathbf{T}_{\mathrm{nn}} \frac{\mu}{\mu_{0}} \gamma \dot{\tilde{E}}+j \lambda_{0} \mathbf{T}_{\mathrm{nL}} \dot{\tilde{\sigma}}=\dot{F}_{1}(Q), \quad Q \in D_{n} \\
\dot{\tilde{\sigma}}(Q)-\chi \mathbf{S}_{\mathrm{LL}} \dot{\tilde{\sigma}}-\chi \mathbf{S}_{\mathrm{Ln}} \frac{\mu}{\mu_{0}} \gamma \dot{\tilde{E}}=\dot{F}_{2}(Q), \quad Q \in L
\end{gathered}
$$

Eqns. (17) and (18) denote:

$$
\begin{gathered}
\mathrm{T}_{\mathrm{nn}} \frac{\mu}{\mu_{0}} \gamma \dot{\tilde{E}}=\int_{D_{n}} \frac{\mu(M)}{\mu_{0}} \gamma(M) \dot{\tilde{E}}(M) T(Q, M) d S_{M}, \quad Q \in D_{n}, \\
\mathrm{~T}_{\mathrm{nL}} \dot{\tilde{\sigma}}=\int_{L} \dot{\tilde{\sigma}}(M) T(Q, M) d L_{M}, \quad Q \in D_{n}, \\
\mathbf{S}_{\mathrm{LL}} \dot{\tilde{\sigma}}=\chi \int_{L} \dot{\tilde{\sigma}}(M) S(Q, M) d L_{M}, \quad Q \in \mathrm{L}, \\
\mathrm{S}_{\mathrm{Ln}} \frac{\mu}{\mu_{0}} \gamma \dot{\tilde{E}}=\chi \int_{D_{n}} \frac{\mu(M)}{\mu_{0}} \gamma(M) \dot{\tilde{E}}(M) S(Q, M) d S_{M}, \quad Q \in L .
\end{gathered}
$$

System (17) - (18) is solved by reducing it to system of algebraic equations, replacing integrals with finite sums. Integration contour $\mathrm{L}$ is divided into $\mathrm{n}$ sections $\Delta \mathrm{L} . \sigma$ is considered constant and equal to its value in centre of segment on each segment. Then elements of matrices (20) and (21) with linear integrals can be calculated from ratios

$$
\begin{gathered}
\mathbf{S}_{\mathrm{ij}}=-x \int_{\Delta L_{j}} S(Q, M) d L_{j}, i \neq j, \\
\mathbf{S}_{\mathrm{ii}}=1-\frac{\lambda}{\pi} \int_{\Delta L_{j}} S(Q, M) d L_{j} .
\end{gathered}
$$

We calculate integral over $\Delta L_{\mathrm{j}}$ using Simpson formula, dividing $\Delta L_{\mathrm{j}}$ into $m$ parts

$$
\begin{aligned}
& \int_{\Delta L_{j}} S\left(Q_{i}, M\right) d L_{j}=\frac{\Delta L_{j}}{3 m}\left(S\left(Q_{i}, M_{0}\right)+4 S\left(Q_{i}, M_{1}\right)+\right. \\
& \left.2 S\left(Q_{i}, M_{2}\right)+\ldots+4 S\left(Q_{i}, M_{m-1}\right)+S\left(Q_{i}, M_{m}\right)\right) .
\end{aligned}
$$


Point $M$ approaches point $Q$ when calculating diagonal coefficients $S_{\text {ii }}$ using formula (24), and, if their coordinates coincide, integral in expression (24) has peculiarity that was studied in [10]. Select neighbourhood of point and denote it $\delta L_{\mathrm{j}}$ to take into account peculiarity when calculating integral by formula (24) on segment $\Delta L_{\mathrm{j}}$. Now integral over two halves of $\Delta L_{\mathrm{j}}-\delta L_{\mathrm{j}}$ is found by formula (25), and integral over $\delta L_{\mathrm{j}}$ is calculated by ratio [10]

$$
\int_{\delta L_{\mathrm{j}}} S\left(Q_{i}, M\right) \cong \frac{\cos \left(\bar{S}_{Q_{j}}, \bar{e}_{Z}\right)}{\rho_{Q_{j}}} \ln \frac{16 \rho_{Q_{j}}}{\delta L_{\mathrm{j}}} \delta L_{\mathrm{j}} .
$$

Ratio for calculation diagonal coefficients of matrix $\mathbf{S}$ has view taking into account (24)

$$
\mathbf{S}_{\mathrm{ii}}=1-\frac{\lambda}{\pi}\left(\int_{\Delta L j-\delta L_{j}} S\left(Q_{i}, M\right) d L_{j}+\frac{\cos \left(\bar{S}_{Q_{j}}, \bar{e}_{Z}\right)}{\rho_{Q_{j}}} \ln \frac{16 \delta_{Q_{j}}}{\delta L_{j}} \delta L_{\mathrm{j}}\right) .
$$

We divide area of integration $D_{\mathrm{n}}$ into rectangles $\Delta \mathrm{S}=2 \mathrm{a} \times 2 \mathrm{~b}$ to calculate elements of matrices (19) and (22). Then, elements of matrix $\mathbf{T}$ are calculated [13]:

$$
\begin{gathered}
\mathbf{t}_{\mathrm{ij}}=T\left(Q_{i}, M_{\mathrm{j}}\right) \Delta S_{M \mathrm{j}}, i \neq j \\
\mathbf{t}_{\mathrm{ii}}=4 a b\left(\ln \frac{8 \rho_{Q_{i}}}{\sqrt{a^{2}+b^{2}}}-\frac{1}{2}\left(1+\frac{a}{b} \operatorname{arctg} \frac{b}{a}+\frac{b}{a} \operatorname{arctg} \frac{a}{b}\right)\right) .
\end{gathered}
$$

System of algebraic equations that approximates system of integral Eqns. (1) - (2) has view

$$
\begin{aligned}
& \overline{\dot{\tilde{E}}}+j \lambda_{0} \mathrm{~T}_{\mathrm{nn}} \frac{\mu}{\mu_{0}} \gamma \overline{\dot{\tilde{E}}}+j \lambda_{0} \mathrm{~T}_{\mathrm{nL}} \dot{\overline{\tilde{\sigma}}}=\overline{\dot{F}}_{1}, \\
& \overline{\dot{\sigma}} \chi \mathbf{S}_{\mathrm{LL}} \overline{\dot{\tilde{\sigma}}} \chi \mathrm{S}_{\mathrm{Ln}} \frac{\mu}{\mu_{0}} \gamma \overline{\dot{\tilde{E}}}=\overline{\dot{F}}_{2},
\end{aligned}
$$

where,

$$
\begin{gathered}
\dot{\vec{F}}_{1}=-j \lambda_{0} \mathbf{T}_{\mathrm{nk}} \dot{\tilde{\delta}}+\overline{\dot{F}_{1}^{0}}, \\
\dot{\dot{F}}_{2}=\chi \mathbf{S}_{\mathrm{Lk}} \dot{\tilde{\delta}}, \\
\overline{\dot{F}_{1}^{0}}=\frac{\dot{\tilde{e}}_{e x t}(Q)}{2 \pi \sqrt{\rho_{Q}}} .
\end{gathered}
$$

System (30) - (31) is written in complex form. We write Eq. (30) in following view

$$
\overline{\dot{E}}+j \lambda_{0} \mathrm{~T}_{\mathrm{nn}} \frac{\mu}{\mu_{0}} \gamma \overline{\dot{\tilde{E}}}=\overline{\dot{F}}_{11},
$$

where,

$$
\overline{\dot{F}}_{11}={\overline{F_{1}}}_{1}-j \lambda_{\mathrm{o}} \mathrm{T}_{\mathrm{nL}} \overline{\dot{\sigma}}=\overline{\dot{F}}_{1}-\overline{\dot{F}}_{3} .
$$

Eq. (35) is solved by direct method. Calculation formulas for determination active and reactive components of electric field strength for our case have view [13]

$$
\begin{gathered}
\overline{\tilde{E}}_{a}=\left[\mathbf{I}+(\mathbf{T})^{2}\right]^{-1}\left(\bar{F}_{11 a}+\mathbf{T} \bar{F}_{11 r}\right), \\
\overline{\widetilde{\mathrm{E}}}_{\mathrm{r}}=\overline{\mathrm{F}}_{11 \mathrm{a}}-\mathrm{T} \overline{\widetilde{\mathrm{E}}}_{\mathrm{a}},
\end{gathered}
$$

where, $\mathbf{I}$ is unitary matrix, and matrix $\mathbf{T}$ is determined by ratio

$$
\mathbf{T}=\lambda_{0} \mathbf{T}_{\mathrm{nn}} \frac{\mu}{\mu_{0}} \gamma
$$

We write Eq. (31) to solve it in following view

$$
\overline{\dot{\tilde{\sigma}}}-\chi \mathbf{S}_{\mathrm{LL}} \overline{\tilde{\tilde{\sigma}}}=\overline{\dot{F}}_{22},
$$

where,

$$
\overline{\dot{F}}_{22}=\overline{\dot{F}}_{2}+\chi \mathrm{S}_{\mathrm{Ln}} \frac{\mu}{\mu_{0}} \gamma \overline{\dot{\tilde{E}}}=\overline{\dot{F}}_{2}+\overline{\dot{F}}_{4}
$$

We obtain two independent systems of linear equations that allow us to calculate active $\overline{\tilde{\sigma}}_{a}$ and reactive $\overline{\tilde{\sigma}}_{r}$ components of density of coupled magnetization currents after division active and reactive components of Eq. (40)

$$
\begin{aligned}
& \overline{\tilde{\sigma}}_{a}-\chi \mathbf{S}_{\mathrm{LL}} \overline{\tilde{\sigma}}_{a}=\bar{F}_{22 \mathrm{a}}, \\
& \overline{\tilde{\sigma}}_{r}-\chi \mathbf{S}_{\mathrm{LL}} \overline{\tilde{\sigma}}_{r}=\bar{F}_{22 r} .
\end{aligned}
$$

System (30) - (31) is solved by iterative method [10]. We set initial distribution of coupled currents and solve first equation of system at first step. We determine distribution of induced currents in runner's copper-plated surface. We solve second equation of system and determine distribution of coupled currents. We again solve first equation of system at second iteration step. We check fulfilment of condition for required solution accuracy

$$
E_{\mathrm{n}+1}-E_{\mathrm{n}} \leq \mathcal{E}
$$

where: $\mathcal{E}$ - required solution accuracy;

$n$ - iteration step.

If condition (44) is not carried out, we take next iteration step. If condition is carried out, we end process of calculation of coupled and induced currents. Active components of magnetic induction along $\rho$ and $Z$ axes are determined [10]:

$$
\begin{aligned}
& B_{\rho a}(Q)=-\frac{\mu_{0}}{4 \pi} \sum_{j=1}^{n} \sigma_{a}\left(M_{j}\right) \frac{Z_{Q}-Z_{M_{j}}}{\rho_{Q} \sqrt{\rho_{Q} \rho_{M_{j}}}} f_{1}(k) \Delta L_{M_{j}}- \\
& -\frac{\mu_{0}}{4 \pi} \sum_{v=1}^{m} \delta_{a}\left(N_{v}\right) \frac{Z_{Q}-Z_{M_{v}}}{\rho_{Q} \sqrt{\rho_{Q} \rho_{N_{v}}}} f_{1}(k) \Delta S_{N_{v}} ; \\
& B_{\text {Za }}(Q)=\frac{\mu_{0}}{4 \pi} \sum_{j=1}^{n} \sigma_{a}\left(M_{j}\right) \frac{1}{\rho_{Q} \sqrt{\rho_{Q} \rho_{M_{j}}}}\left(\rho_{Q} f_{1}(k)+\rho_{M} f_{2}(k)\right) \Delta L_{M_{j}}+ \\
& +\frac{\mu_{0}}{4 \pi} \sum_{v=1}^{m} \delta_{a}\left(N_{v}\right) \frac{1}{\rho_{Q} \sqrt{\rho_{Q} \rho_{N_{v}}}}\left(\rho_{Q} f_{1}(k)+\rho_{N} f_{2}(k)\right) \Delta S_{N_{v}} .
\end{aligned}
$$

Reactive component of induction is calculated using formulas similar to (45) and (46). 


\section{ALGORITME OF CALCULATION OF INDUCTION IN CLEARANCE OF TLIM}

Algorithm of calculation of magnetic field induction in TLIM clearance is developed, diagram of which is shown in Figure 4.
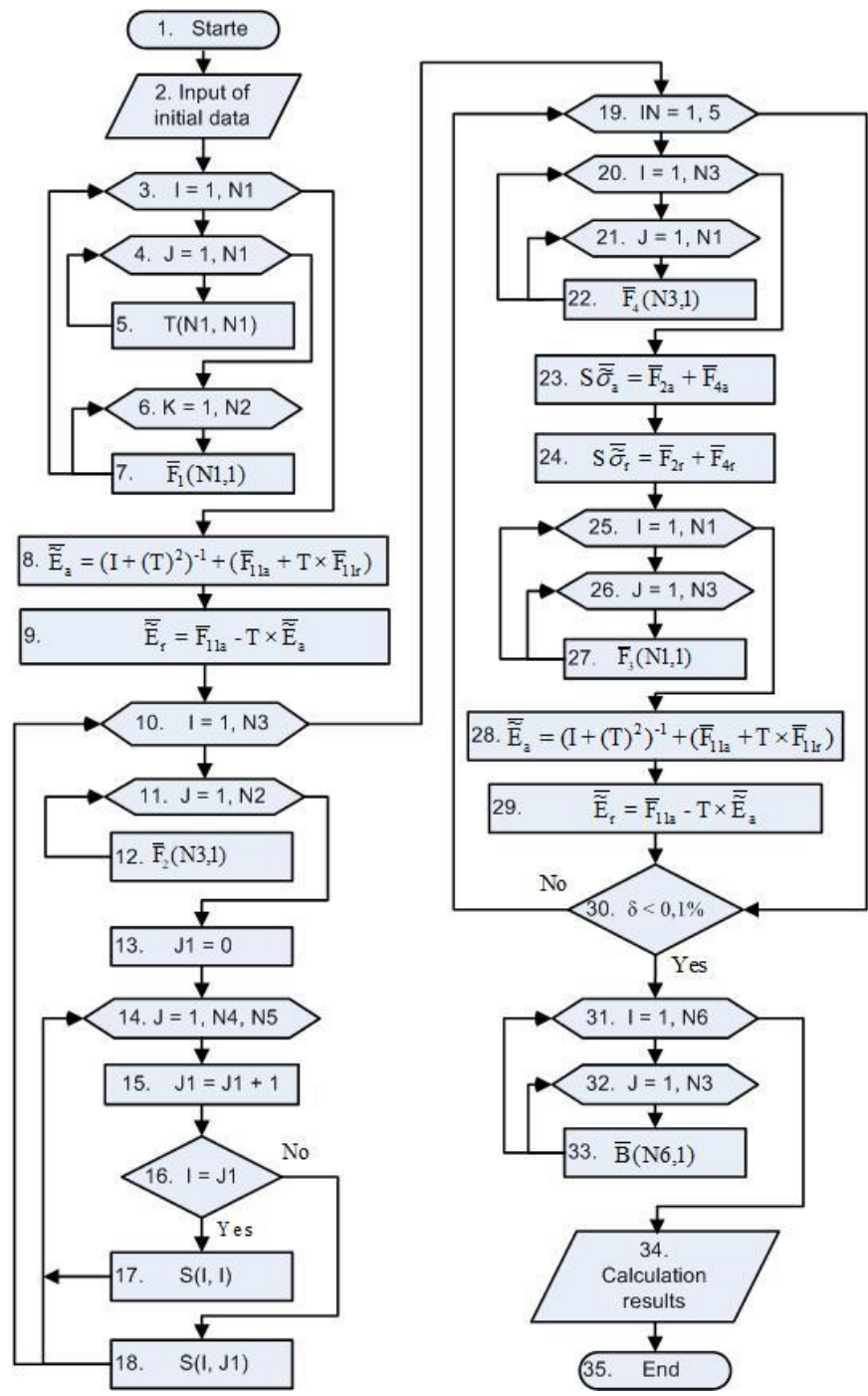

Figure 4. Scheme of algorithm of calculation of induction in clearance TLIM

Step 2 - declaration of array sizes and input of initial data.

Step 3 - cycle for formation of matrix $\mathbf{T}$ is set (steps 4 and 5) and vector $\bar{F}_{1}$ (steps 6 and 7).

Step 8 - solution of Eq. (30) relatively to active $\overline{\tilde{E}}_{a}$ (37) and step 9 - relatively to reactive $\overline{\tilde{E}}_{\mathrm{r}}(38)$ components of electric field strength.

Step 10 - cycle is set to form vector $\bar{F}_{2}$ (steps 11 and 12) and matrix S (steps 13 - 18).

Step 19 - cycle of iterations between first (30) and second (31) equations of system is specified (cycle was limited to 5 steps in calculations).

Step 20 - cycle of vector $\bar{F}_{4}$ formation is set (steps 21 and 22).

Step 23rd - solution of Eq. (31) relatively to active $\overline{\tilde{\sigma}}_{a}(42)$ and step 24 - relatively to reactive $\overline{\tilde{\sigma}}_{\mathrm{r}}$ (43) components of magnetization currents.

Step 25 th - cycle is set to form vector $\bar{F}_{1}$ (steps 26 and 27).
Step 28th - solution of Eq. (30) relatively to active $\overline{\tilde{E}}_{a}$ (37) and step 29th - relatively to reactive $\overline{\tilde{E}}_{\mathrm{r}}$ (38) components of electric field strength.

Step 30th - check for required solution accuracy.

Steps 31 - 33: calculation of induction distribution in clearance of TLIM.

Step 34 - output of calculation results.

\section{RESEARCH RESULTS}

Above mathematical model was used to calculate induction in clearance of three-phase TLIM used for drive of highvoltage disconnectors (Figure 1) [12]. Motor parameters are given in appendix 1.

Integration area $D$ n (Figure 3) was divided into 100 rectangles with section $2 \mathrm{a} \times 2 \mathrm{~b}(\mathrm{~N} 1=100)$ in mathematical model. Matrix $\mathbf{T}$ has dimension of $100 \times 100$ in this case.

Cutset of each of 18 coils of stator winding was divided into 6 rectangles $(\mathrm{N} 2=18 \times 6=108)$.

Integration contour $L$ (Figure 3 ) was divided into 108 sections $\Delta L(\mathrm{~N} 3=108)$, within which approximation was performed using Simpson formula (23) for case $m=4$ $(\mathrm{N} 4=108 \times 4=432 ; \mathrm{N} 5=4)$. $\mathrm{S}$ has dimension of $108 \times 108$ in this case.

Functions $f_{1}(k)$ and $f_{2}(k)$ were preliminarily calculated using formulas (7) and (8) from tabular values of elliptic integrals of first $\mathrm{K}(k)$ and second $\mathrm{E}(k)$ kind. We used arrays $f_{1}(k)$ and $f_{2}(k)$ for 101 points in calculations.

Magnetic field induction was calculated for 79 points along motor air clearance. Values of physical parameters taken in calculation of induction are given in appendix 2 .

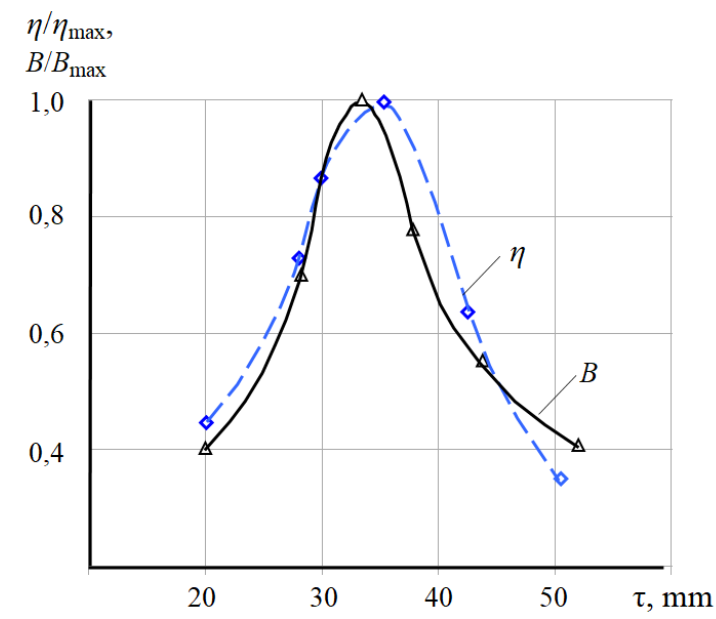

Figure 5. Calculated $B / B_{\max }=f(\tau)$ and experimental $\eta / \eta_{\max }=f(\tau)$ dependences

It is shown results of calculation of dependence of magnetic induction in TLIM clearance on value of pole division $B=f(\tau)$ (solid curve) in Figure 5. Parameters of stator winding coils remained unchanged in calculations. Pole division $\tau$ was changed due to toothed zone of stator iron circuit.

It can be seen from graph that there is area of values of pole division $\tau$ of motor, in which induction in clearance of motor takes maximum value.

Figure 5 is also shown experimental dependence of efficiency of motor from value of pole pitch $\eta=f(\tau)$ (dashed curve), obtained on physical model [14], which has similar 
parameters. Analysis of graphs (Figure 5) shows that area of optimal values of pole division in calculated and experimental dependences practically coincide and it confirms reliability of calculated data.

Figure 6 is shown calculated dependence of induction B in engine clearance on thickness of runner's magnetic core $\Delta$ for engine having pole division $\tau=36 \mathrm{~mm}$. Diameter of runner on steel is $18 \mathrm{~mm}$., runner's magnetic core is solid steel bar at $\Delta=9$ $\mathrm{mm}$, and it is tubular runner at $\Delta<9 \mathrm{~mm}$. Function $B=f(\Delta)$ also has maximum in area of optimal values of runner's magnetic core thickness as can be seen from graph (Figure 6).

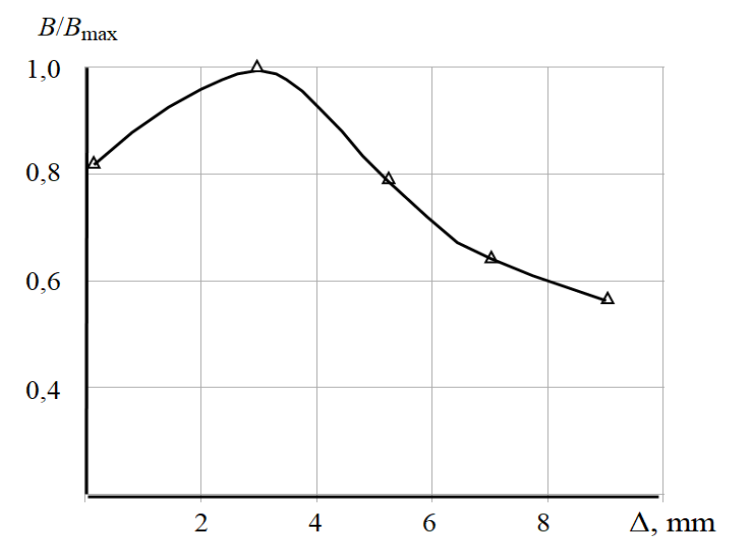

Figure 6. Calculated dependence $B=f(\Delta)$

\section{EXPERIMENTAL VERIFICATION OF THE DESIGN DATA $\ddot{E}$}

Dependence of TLIM energy characteristics on pole pitch value was studied out on physical model, parameters of which coincide with parameters of calculated mathematical model. Results of research of physical model are given by Ochrimenko [14]. Optimum pole pitch was $\tau_{\text {opt.physical }}=35 \mathrm{~mm}$.

We also carried out research of mathematical model of TLIM stator (actually engine without moving part) with same geometric dimensions. Research results are published in [15]. Stator electromagnetic field is described by one Fredholm integral equation of 2nd kind for density of coupled magnetization currents [16]

$$
\dot{\sigma}(Q)+\frac{\lambda}{\pi} \int_{L} \sigma(M) S(Q, M) d L_{M}=\dot{F}_{1}(Q)
$$

where the designations are the same as in Eq. (2).

Eq. (47) is similar to Eq. (2), and resulting relations for calculation of magnetic induction are similar to relations (45) and (46). In general, Mathematical model of stator and its software implementation is much simpler than mathematical model of engine, electromagnetic field in which is described by two Fredholm integral equations of 2nd kind (1) and (2). Calculated optimal value of pole pitch for TLIM stator was $\tau_{\text {opt.stator }}=23 \mathrm{~mm}$ [15]. That is, areas of optimal values of pole pitch of engine and separately engine stator do not coincide.

Comparison of optimal values of pole pitch of physical TLIM model $\left(\tau_{\text {opt.physical }}=35 \mathrm{~mm}\right)$ with optimal pole pitch values calculated using mathematical model presented here $\left(\tau_{\text {opt.mathematic }}=34 \mathrm{~mm}\right)$ showed coincidence sufficient for engineering calculations. At the same time, it was concluded that it is necessary to take into account geometric parameters of moving part of engine (runner) in TLIM mathematical model.

\section{CONCLUSIONS}

Presented mathematical model covers the entire TLIM class and does not require the introduction of special coefficients that take into account the presence of longitudinal edge effects and depend on the ratio of the geometric parameters of the engine. Model makes it possible to calculate induction in the TLAM gap taking into account its real geometric structure, dimensions and physical properties used by material.

Mathematical model of TLIM can be used to calculate quasi-stationary fields of axisymmetric electromagnetic systems described by two Fredholm integral equations of second kind relatively to density of coupled magnetization currents at environments interface and density of induced currents in conductors.

Dependences of induction in clearance of TLIM on value of pole division and on thickness of magnetic conductive part of runner are investigated. Extreme nature of these dependencies and presence of areas of optimal values of pole division and thickness of magnetic conductive part of runner in which induction in engine clearance is maximum are shown.

Described mathematical model can be used at design stage in order to determine optimal geometric dimensions of TLIM.

Further research involves improvement of development of mathematical model, taking into account dynamics of runner movement and obtaining of possibility of calculation of working characteristics of TLIM.

This problem requires research of question of assignment of rational lengths of sections of fragmentation $\Delta \mathrm{L}, \Delta \mathrm{S}, \mathrm{Dn}$, number $\mathrm{m}$ of parts of fragmentation of sectiont $\Delta \mathrm{Lj}$ for $\mathrm{i}=\mathrm{j}$. (optimality condition is minimum number of integration points with acceptable accuracy of calculation of induction in engine gap or tractive force of engine). Designed calculations of engine geometry will also require taking into account degree of saturation of magnetic circuit. As a result, it will be possible to calculate optimal (minimum) geometric dimensions for given tractive forces, operating modes and used materials.

\section{REFERENCES}

[1] Website International Symposium on Linear Drives for Industry Applications. https://archiveweb.epfl.ch/ldia2019.epfl.ch/.

[2] Tiunov, V. (2018). Practical application and methods of calculation for linear induction motors. International Multi-Conference on Industrial Engineering and Modern Technologies (FarEastCon), Vladivostok, pp. 1-6. http://dx.doi.org/10.1109/FarEastCon.2018.8602929

[3] Musolino, A., Raugi, M., Rizzo, R., Tucci M. (2015). Optimal design of EMALS based on a double-sided tubular linear induction motor. In IEEE Transactions on Plasma Science, 43(5): 1326-1331. https://doi.org/10.1109/TPS.2015.2413675

[4] Musolino, A., Raugi, M., Rizzo, R., Tucci M. (2014). Force optimization of a double-sided tubular linear induction motor. Magnetics, IEEE Transactions on. 50(12):

1-11. 
[5] Shvydkiy, E.L., Smolyanov, I. A., Sarapulov, F., Bolotin, K.E. (2017). Calculation methods of tubular linear induction motor. IEEE Conference of Russian Young Researchers in Electrical and Electronic Engineering (EIConRus), St. Petersburg, pp. 1579-1580. https://doi.org/10.1109/EIConRus.2017.7910874

[6] Consolo, V., Musolino, A., Rizzo, R., Sani, L., Simonelli, C. (2019). Design and simulation of a double-mover tubular linear induction motor for high thrust force. 12th International Symposium on Linear Drives for Industry Applications

(LDIA). https://doi.org/10.1109/LDIA.2019.8771008

[7] Yan, L., Li, W., Jiao, Z., Chen, C., Chen, I. (2015). Key Parameters Optimization of a Novel Tubular Double Excitation Windings Linear Switched Reluctance Motor. In: Bai S., Ceccarelli M. (eds) Recent Advances in Mechanism Design for Robotics. Mechanisms and Machine Science, vol 33. Springer, Cham. https://doi.org/10.1007/978-3-319-18126-4_19

[8] Esfahanian, H.R., Hasanzadeh, S., Heydari, M. (2018). Performance analysis and force components improvement of an tubular linear induction motor used in a novel magnetic train by 3-D FEM. Electrical Engineering (ICEE), Iranian Conference on, Mashhad, pp. 1368-1372. https://doi.org/10.1109/ICEE.2018.8472417

[9] Yan, L., Zhang, L., Wang, T., Jiao, Z., Chen, C.Y., Chen, I.M. (2013). Magnetic field of tubular linear machines with dual halbach array. Progress in Electromagnetics Research, 136: 283-299. https://doi.org/10.2528/PIER12110302

[10] Tozoni, O.V. (1975). Metod vtorichnykh istochnikov v elektrotekhnike [Method of secondary sources in electrical engineering]. Moscow. Energy Publ.

[11] Petrushenko, E.I., Tozoni, O.V. (1965). Raschet polia v magnitnykh sistemakh peremennogo toka [Calculation of the field in magnetic systems of alternating current]. Science and technology in the urban economy. Kiev, 3: 3-18. [in Russian].

[12] Kvachev, G.S., Melnichenko G.I. (1969). Certificate of authorship 233782, USSR, H02c. Jelektroprivod dlja kommutacionnyh apparatov [Electric drive for switching devices]. (Bull. №. 3). [in Russian].https://patents.su/2233782-ehlektroprivod-dlya-kommutacionnykhapparatov.html.

[13] Romanovich, S.S., Fedchun, L.V. (1972). Raschet na TsVM vikhrevykh tokov v osesimmetrichnykh provodnikakh [Calculation on a digital computer of eddy currents in axisymmetric conductors]. Cybernetics and Computer Science, 17: 31-37. [in Russian].

[14] Ochrimenko, V. (2020). Étude d'un modèle physique du moteur asynchrone linéaire cylindrique. Le tendenze e modelli di sviluppo della ricerche scientifici. 13 marzo. Roma, Italia. Tomo, 1: 71-75. [in French]. https://doi.org/10.36074/13.03.2020.v1.23

[15] Ochrimenko, V. (2020). Étude d'un modèle mathématique du moteur asynchrone linéaire cylindrique. Les tendences actuelles de la mondialisation de la science mondiale. 1 avril. Monaco, Principauté de Monaco, 1: 77-84. [in https://doi.org/10.36074/03.04.2020.v1.27
[16] Tozoni, O.V. (1967). Raschet jelektromagnitnyh polej na vychislitel'nyh mashinah [Calculation of electromagnetic fields on computers]. Kiev, Tehnika. [in Russian].

\section{NOMENCLATURE}

$\begin{array}{ll}\text { TLIM } & \text { tubular linear induction motor } \\ \mathrm{Q} & \text { fixed point of integration } \\ \mathrm{M} & \text { current integration point } \\ \dot{E} & \text { electric field strength complex, } \mathrm{V} / \mathrm{m} \\ \mathrm{S} & \text { stator winding area, } \mathrm{m}^{2} \\ \mathrm{D} & \text { runner's copper-plated surface area, } \mathrm{m}^{2} \\ \mathrm{Z} & \text { coordinate of cylindrical coordinate system, } \mathrm{m}\end{array}$

\section{Greek symbols}

$\begin{array}{ll}\dot{\sigma} & \begin{array}{l}\text { density complex of coupled magnetization } \\ \text { currents, } \mathrm{A} / \mathrm{m}^{2}\end{array} \\ \mu & \begin{array}{l}\text { magnetic permeability } \\ \text { electrical conductivity, } \Omega \mathrm{M} \cdot \mathrm{m}\end{array} \\ \gamma & \begin{array}{l}\text { conductivity current density complex } \\ \dot{\delta}\end{array} \\ \omega=2 \pi f & \begin{array}{l}\text { angular frequency of current, } \mathrm{rad} / \mathrm{s} \\ \rho\end{array} \\ \chi & \begin{array}{l}\text { coordinate } \rho \text { of cylindrical system coordinate, } \mathrm{m} \\ \text { coefficient determined by ratio (4) }\end{array}\end{array}$

\section{Subscripts}

$\begin{array}{ll}\text { a } & \text { active component } \\ \text { c } & \text { coil } \\ \text { ext } & \text { external } \\ \mathrm{r} & \text { reactive coomponent } \\ \text { st } & \text { steel }\end{array}$

\section{APPENDIX}

\section{(1) Parameters of the TLIM}

Geometrical dimensions (Figure 1).

Stator housing: outer diameter $\mathrm{d}_{1}=60 \mathrm{~mm}$, inner diameter $\mathrm{d}_{2}=55 \mathrm{~mm}$, length - $240 \mathrm{~mm}$.

Stator magnetic core - solid steel (Cт. 3) clips: outer diameter $\mathrm{d}_{2}=53 \mathrm{~mm}$, inner diameter $\mathrm{d}_{3}=50 \mathrm{~mm}$, clip thickness $1.5 \mathrm{~mm}$. Stator winding coil: outer diameter $\mathrm{d}_{3}=49 \mathrm{~mm}$, inner diameter $25 \mathrm{~mm}$, thickness $\mathrm{h}=9.3 \mathrm{~mm}$.

Runner. Solid bar (St. 3) with diameter of $\mathrm{d}_{4}=19 \mathrm{~mm}$, length $\mathrm{L}_{1}=595 \mathrm{~mm}$. Conductive part - copper overlay of thickness $1.5 \mathrm{~mm}$, length $\mathrm{L}_{2}=507 \mathrm{~mm}$.

Stator winding: 18 coils, number of turns -1520 . Connecting circuit - star. Supply voltage -220 V. Supply voltage frequency $50 \mathrm{~Hz}$. Pole division - $36 \mathrm{~mm}$. Number of pole pairs -3 .

(2) Parameters of mathematical models

$\mu_{0}=4 \pi \cdot 10^{-7} \mathrm{H} / \mathrm{m}$

$\mu_{\mathrm{st}}=100 \mathrm{H} / \mathrm{m}$

$\gamma(\mathrm{M})=52,5 \cdot 10^{6} 1 /(\Omega \cdot \mathrm{m})$

$\lambda_{0}=\omega \cdot \mu_{0} /(2 \pi)=6,28 \cdot 10^{-5}$ 